\title{
Eurípedes e Pasolini. $\bigcirc$ mundo mítico rural e o mundo objetivo da cidade: educação e passagens
}

Milton José de Almeida ${ }^{*}$

Resumo: Este artigo versa sobre a passagem do mundo mítico e agrícola para o mundo prático e objetivo da cidade em suas dimensôes de violência e desagregação social, como se apresentam na tragédia Medeia, de Eurípedes, e no filme do mesmo nome, de Pier Paolo Pasolini. Essa passagem é representada pela aliança social dos personagens Medeia e Jasão e pela quebra dessa aliança. A educação dos personagens, o poder econômico, a perspectiva de miséria e desagregaçáo da família conduzem os interesses e a violência das relaçôes afetivas e sociais.

Palavras-chave: Pasolini; Eurípedes; Medeia; educação; cidade.

Euripedes and Pasolini. The mythical rural world and the objective urban world: education and passages

Abstract: This article discusses the transition from the ancient peasant and mythical world to the objective and practical world of the city in its dimensions of violence and social disruption, as found in Euripides' tragedy Medea and in the movie of the same name by Pier Paolo Pasolini. This passage is represented by the social alliance of the characters Medea and Jason and the breaking of this alliance. The education of the characters, the economic power, the expectancy of poverty and family breakdown drive the interests and the violence of affective and social relationships.

Key words: Pasolini; Euripedes; Medea; education; city.

A violência é parte essencial e vital do homem e se produz indiscriminadamente entre as pessoas de diferentes condiçôes de vida e categorias sociais. A violência lateja na vida da cidade em movimentos desagregadores e, para que a cidade permaneça tranquila, esses movimentos devem ser deslocados de seus atores individuais para o universo da educação, do direito, da justiça, da cultura, das religiôes - instituiçóes que administram a violência social e individual.

Este texto versa sobre esse assunto e sobre a passagem do mundo mítico e agrícola para o mundo prático e objetivo da cidade, tal como é interpretada no filme Medeia

Professor e pesquisador do Laboratório de Estudos Audiovisuais - Olho, Departamento de Educação, Conhecimento, Linguagem e Arte (Delart) da Faculdade de Educação da Unicamp, Campinas, SP, Brasil. 
a tragédia de mesmo nome ${ }^{1}$. Essa passagem é representada pela relação amorosa e matrimonial entre os personagens Medeia e Jasão. Esta será, desde o início, uma exposição escrita em referências cruzadas, que solicita do leitor a colaboração no entendimento do assunto, que inicio diretamente, sem preâmbulos.

Jasão é o novo homem da cidade, objetivo e carreirista, e renega Medeia e seus dois filhos, para casar com a filha do rei de Corinto, o que representa nova ascensão social para ele. É claro que "objetivo e carreirista" não são palavras do texto trágico, nós as usamos atualmente para designar um tipo geral e comum hoje em nosso momento social, econômico e político.

Quando lemos hoje, num livro, a tragédia Medeia, escrita por Eurípedes em 431 a.C., essa leitura que acontece 2441 anos depois de sua escritura é inevitavelmente mais rica, pois vem acompanhada das inúmeras interpretaçóes que recebeu ao longo do tempo. Cada época, cada década, cada ano, cada leitor a lê do seu jeito, a interpreta segundo suas necessidades e desejos ancorados na sua vida presente e nas imperceptíveis necessidades que o momento, a história e a sociedade em que vive o levam a ler e a escrever. É o que acontece com todo texto e toda obra que estudamos e a respeito dos quais escrevemos.

Assim é que a personagem mulher Medeia e o personagem homem Jasão, nascidos para o teatro há mais de dois mil e quatrocentos anos, reviveram e revivem inúmeras vezes, em muitas línguas e locais diferentes.

Ao longo desses dois milênios e tanto, quem leu esses textos, em diferentes suportes - o papel impresso foi usado depois de quase dois milênios de quando essa tragédia foi apresentada nos concursos trágicos gregos -, o leu e o representou, imaginou e recriou inúmeras Medeias e Jasóes diferentes dos originais.

Esses dois personagens são míticos e literários: podem morrer na trama da história que está sendo contada, mas renascem, revivem e repetem as mesmas açóes toda vez que alguém abre o livro e começa a ler. Jasão e Medeia vivem eternamente se apaixonando, traindo-se; vivem eternamente a violência de seus desejos, das suas almas que precisam beber a traição e a vingança, das suas almas inquietas que arrasam todos que cruzam seus caminhos.

Medeia e Jasão partiram juntos da Cólquida, mas logo, mesmo juntos, seus passos estavam trilhando mundos diferentes. Lembremos que são personagensmito e não personagens-drama, como os da literatura romântica e contemporânea. Eurípedes não nos mostra muitas nuances e possibilidades de transformaçáo de seus personagens. Medeia e Jasão irão, do começo ao fim da tragédia, obedecer a seus desejos determinados pelos deuses, pelo Destino e, é claro, pelo autor e, ao fundo, pela sociedade em que viveu.

I. Para detalhes e versões sobre o mito de Jasão e Medeia, consultar Urutágua, 2007-2008). 
A concisão temporal da tragédia não permite acompanharmos durante anos e anos as transformaçóes lentas dos personagens como num romance ou novela. Tudo acontece na ficção de um agora, momento de crise em que as coisas estão em processo de inexorável desventura, encaminhadas pela fatalidade, pelo destino, pela vingança, pelos sentimentos, pelos ciúmes. $\mathrm{O}$ que ocorreu sabemos, por conhecer o mito ou porque nos informa o coro ou os personagens, como a ama de Medeia, que nos diz logo ao iniciar a peça:

[...] Não teria Medeia, minha dona, então, realizado essa viagem rumo a Iolco com o coração ardentemente apaixonado por Jasão, [...] viveria com Jasão e com seus dois filhos nesta terra, Corinto célebre. Ela se esforçava ao máximo por agradar aos habitantes da cidade que é seu refúgio [...]. Mas agora a inimizade a cerca por todos os lados e ela vê-se ameaçada no que tem de mais precioso: traidor dos filhos e de sua amante, sobe Jasão em leito régio, desposando a filha do rei Creonte, senhor do pais. (Eurípedes, 1991, 10-26, p. 31)

Esse é o começo da tragédia escrita.

No filme Medeia, o diretor começa de outra maneira, mostrando-nos coisas que não vemos no texto grego, e não segue o modelo trágico, e sim o modelo dramático de desenvolvimento da ação. Ou seja, ele vai contar cinematograficamente uma tragédia, expressão de sentimentos aristocráticos, utilizando um modelo narrativo burguês, numa trama com introdução, desenvolvimento e conclusão. É interessante, nesse ponto, observarmos que a essência da tragédia, a história nuclear, permanece; porém, a forma cinema a transforma em tragédia burguesa, cujo exemplo contemporâneo e bem-sucedido é a novela de televisão, que tem os mesmos ingredientes de traição, desejo, casamento, herança, rejeição.

Podemos entrelaçar os três temas deste dossiê: educação, cidadania e pobreza e expressá-los com a história de Medeia e Jasão. Gostaria que o leitor atentasse para o fato de que não vou discutir os temas através da tragédia. Vou tentar mostrá-los para que o leitor os discuta e não espere, se possível, ver aqui realizado o costume metodológico que faz com que pessoas, atos e coisas expressem conceitos já de antemão definidos. Não creio que eu tenha conseguido fazer isso plenamente, mas tive a intenção.

O filme Medeia mostra-nos a educação de Jasão pelo Centauro.

Os centauros, descendentes de Íxion, são seres híbridos, monstros e bestas violentas. Porém, alguns que não têm essa descendência são doces, civilizados, educadores. Aquiles, por exemplo, fora educado por um desses centauros, Quíron, que era seu avô materno. Quíron, diríamos hoje, foi um educador das elites e educou muitos e muitos heróis, personagens de mitos e histórias gregas, como Hércules, Ulisses, Esculápio e também Jasão. 
Nas primeiras cenas do filme Medeia, vemos algumas fases do crescimento e da educação de Jasão que, quando ainda bebê, é entregue a Quíron por Esão, seu pai, moribundo. Essa parte da história, mesmo não detalhada na tragédia de Eurípedes, evidentemente está no seu plano de fundo.

Por que terá o filme começado com esse episódio? Talvez para mostrar que, educado pelo centauro nos valores éticos e morais antigos, Jasão vai traí-los mais tarde, quando tentar vencer no novo mundo de interesses burgueses, como o novo homem pequeno-burguês ou o subproletário contemporâneo, classes sempre retratadas pelo diretor com compaixão e tristeza e, ao mesmo tempo, com dura crítica.

Nessa parte inicial do filme, em diferentes momentos de sua vida de criança até adolescente e jovem, o centauro diz a Jasão diversas coisas, que soam como conselhos de um educador:

Hoje você faz cinco anos e eu the quero contar a verdade.

Tudo é sagrado,

tudo é sagrado.

Lembre-se, meu filho:

não há nada de natural na natureza.

Um deus esconde-se em todos os lugares que você olhar.

Se ele não está, ele deixa marcas de sua presença sagrada.

O silêncio, o cheiro da grama, of frescor da água doce.

Sim, tudo é sagrado.

Mas a santidade também é uma maldição.

Enquanto os deuses amam, também odeiam.

Talvez vocêpense que, além de mentiroso, sou também muito poético.

Mas para o homem antigo, os mitos e rituais são experiências concretas incluidas mesmo na sua existência quotidiana.

Para ele, a realidade é uma unidade totalmente perfeita, e a emoção que sente ao ver um céu de verão, por exemplo, é igual à mais infernal, pessoal experiência do homem moderno.

O que não é possivel ver, infelizmente, sáo os erros aos quais você será conduzido. Quem sabe quantos serão?

O que o homem testemunhou no cultivo dos grãos, o que entendeu do renascimento das sementes representa uma lição definitiva: a ressurreição.

Mas essa lição não tem mais utilidade. O que ele recolheu das sementes não faz mais sentido para você. É uma memória distante que não afeta você.

De fato, não há mais deuses.

Quando lemos em algum texto, como aqui, a palavra "educação" e, principalmente, quando é nosso objeto de trabalho e estudos, ela já nos chega constelada 
de sentidos, e é difícil fugir a uma espécie de discronia, pensarmos em educação como pensamos hoje e, ao mesmo tempo, imaginarmos como "naquele tempo" ... e tudo se distorce.

O presente sempre interpreta para si o passado, e com isso o influencia; e o vemos como pertencente ao presente, sem nos darmos conta disso. Um pouco como naquelas aulas ou livros sobre a educação na Grécia antiga, que ninguém sabe como foi, pois só temos textos remanescentes e daqueles pensadores que ficaram documentados. Costuma-se muito escrever sobre a educação atual como se tivesse tido origem na democracia grega. A democracia grega, quando viveu Eurípedes, não era uma democracia popular; dela estavam excluídos tanto o que hoje chamamos povo, quanto os escravos e os estrangeiros - e assim também a educação grega não era uma educação popular. Não havia educação universal, e muito menos pública, e não se frequentavam escolas, como hoje. Ao interpretarmos o passado com nossos propósitos contemporâneos, criamos algumas fábulas acadêmicas e culturais que, repetidas, passam por verdades. Avisa-nos Ortega e Gasset (2010, p. 17), ao referir-se aos padres da Igreja medieval:

Pretender que aqueles frades de cabeça tonsurada foram capazes de entender os conceitos gregos, a idéia de Ser, por exemplo, é ignorar a dimensão trágica que acompanha o acontecer histórico [...]. Na recepção de uma filosofia estrangeira, o esforço mental inverte sua direção, e trabalha, não para entender os problemas, o que as coisas são, mas sim para chegar a entender o que o outro pensou sobre elas e expressou em certos termos. $\mathrm{O}$ termo, ou conceito, não é uma palavra da língua, e sim um signo artificial. Por isso não é entendido sem mais nem menos. Criado em virtude de uma definição, tem-se que chegar ao entendimento desta, que por sua vez, está composta de termos e conceitos. Daí que todo escolasticismo é a degradação de um saber em mera terminologia.

Assim é que o filme foge dessa ilusão de Cronos e não tenta mostrar a história como se fosse naquele tempo, apesar de os cenários e as vestimentas parecerem como tal.

O diretor deixa aparecer cinematograficamente a história de Medeia e Jasão em inúmeras camadas históricas, as quais podemos abrir e interpretar de muitas maneiras.

Por exemplo, alguém pode imaginar que os gregos se vestissem da maneira como aparecem no filme, que falassem daquele jeito e tivessem aquela educação e jeito de se conduzir em sociedade. Há professores que passam filmes históricos para ilustrar suas aulas, e essa educação visual vai passando de um para outro, até nos surpreender, ao vermos os enredos históricos na passarela do carnaval. 
O cenógrafo de Medeia diz:

Eu sempre tento encontrar maneiras de manipular a realidade para acentuar o foco central do filme. Exagero certos detalhes e descarto outros [...]. Tento colocar-me na posição de alguém que viveu neste período, um arquiteto ou designer. Tento me mover dentro deste período e pensar como alguém que viveu lá. Mas, ao mesmo tempo, é muito importante fazer alguns erros, e colocar alguma coisa errada. Para mim, os erros são as coisas mais importantes. Porque se você ver um filme com reconstruçôes perfeitas, isso é chato. Olhe em volta: nada é perfeito na realidade. Assim, se você juntar alguns erros, vai parecer real. (Ferretti, [2005])

\section{II}

Em cena, ao meio do filme, aparece o centauro Quíron duplicado, e vemos o encontro de Jasão com eles: o novo centauro aparece acompanhado do antigo.

Jasão não percebe direito e abraça Quíron com afeto, mas em seguida surpreende-se ao vê-lo em duas figuras e pergunta: "Mas é uma visão?". Quíron responde: "Se é, é você que a produz.".

$\mathrm{O}$ cinema é a forma artística e industrial dos nossos tempos. O diretor, enquanto mostra em seu filme uma história mitológica, alude ao momento contemporâneo: exibe a aliança antiga, o centauro que educou Jasão, e a aliança atual, o centauro moderno, não mais com corpo de cavalo. É uma passagem que revela, também, a transformação de texto literário antigo para texto cinematográfico moderno.

Assim é que vemos, nessa sequência, um momento de cruzamento cinematográfico temporal e histórico: o encontro de Jasão com o centauro, aqui aparecido em dois centauros: o antigo sagrado, que o educou; e o dessacralizado e novo, que lhe vem chamar a atenção para as mudanças que sofreu. Porque Jasão é agora o homem moderno, contemporâneo, que age segundo os valores éticos e morais da nova classe burguesa, valores trocáveis como se trocam moedas entre si, ou moedas por mercadoria; valores abstratos de troca, não mais valores concretos de conteúdo.

Jasão representa o novo mundo do poder das cidades e dos interesses pessoais.

E aqui podemos perceber, numa das camadas de significado do filme, a vida real participando da história do filme: na época em que filmou Medeia, 1969, Maria Callas tinha se tornado amiga íntima e confidente de Pasolini. Passavam muitos momentos em companhia um do outro e durante as filmagens hospedavam-se juntos ${ }^{2}$.

2. Medeia foi filmado na Turquia, na Síria e na Itália: na Toscana, em Roma (em estúdio), em Friuli, no Lido Marechiaro, em Viterbo. 
E, nessa época, Maria Callas sofreu um abalo psicológico por ter sido rejeitada por Aristóteles Onassis, que se casou com Jaqueline Kennedy. Callas havia sido amante dele por quase dez anos e por ele praticamente encerrou sua carreira de cantora de ópera no auge do sucesso. Em 1975, morreram Pasolini e Onassis; e, em 1977, Callas.

Entrelaçam-se e confundem-se no filme, os pares Medeia-Callas, Jasão-Onassis, Jaqueline Kennedy-Glaucia (filha de Creonte, rei de Corinto).

As origens desses personagens da vida real são aquelas do novo homem contemporâneo, não mais dos antigos aristocratas, mas dos novos aristocratas do capitalismo. Medeia-Callas e Jasão-Onassis são de famílias de imigrantes gregos; Glaucia-Jaqueline Kennedy, de origem irlandesa, inglesa, escocesa e francesa, era filha de um rico corretor da bolsa (Creonte) e neta de imigrante irlandês.

Mesmo sendo Medeia a personagem principal e condutora da ação, no filme há a inserção de inúmeras ações e acontecimentos que não fazem parte da tragédia escrita. Lembremos que a história contada na forma tragédia transcorre num dia só, uma estrutura concisa que expressa densos sentimentos humanos e, ao mesmo tempo, mostra o problemático relacionamento entre deuses e homens. Porém o filme estende-se por diversos momentos das vidas de Jasão e Medeia.

Lembrando: no filme, Jasão aparece como representante do novo homem burguês, e no início do filme é-nos mostrado como ele teve uma educação antiga fundada nos valores da fidelidade e da honra - o Centauro. Como no futebol ou nas empresas, seguindo sua ambição material e de prestígio, Jasão resolve repudiar Medeia e se casar com a filha de Creonte: como homem moderno, contemporâneo, Jasão age por interesse. Apesar de também ser de ascendência rica e nobre, casando-se com a filha do rei, ele ingressaria numa família de poder. Lembremos que ele está em uma cidade estrangeira, Corinto, como um imigrante lutando pela sobrevivência.

Com alusóes dramáticas e visuais, o filme coloca Medeia e Jasão na arena de um conflito amoroso trágico, que é também político e ético.

O conflito é visto entre dois tempos históricos: Medeia aparece como vinda do tempo mítico e vivendo interiormente nele - o tempo do mundo agrícola, das crenças nos deuses propiciadores e na honra da palavra. Tempo também de vingança e violência sanguinárias. Jasão veio de um mundo antigo, porém mais urbano. Lesado em seus direitos de herança, é recriado no filme como o novo homem burguês contemporâneo, aquele que age por interesse, e não mais por afeto ou sentimento.

Em boa parte dos filmes pasolinianos, os personagens burgueses são tratados como personagens-conceito, não são propriamente humanos, são humanos de uma maneira teórica. Representam as categorias de novo burguês ou pequeno-burguês: 
o exemplo mais radical é seu filme Teorema, em que os personagens-burgueses se movem com frieza glacial.

Medeia representa a antiga aristocracia rural, e Jasão, o novo homem do capitalismo. Isso no filme, arte contemporânea. Não, certamente, na tragédia de Eurípedes, ou nas tragédias gregas. Nessas estão representados forças e sentimentos de deuses e homens, presentes na sociedade grega, e não classes sociais e outras categorias intelectuais com que estamos acostumados a pensar.

Lembremos que, no filme, vemos uma reapresentação da tragédia de Eurípedes em forma cinematográfica, uma interpretação verbal e visual enriquecida pelas discussóes de séculos antes e pelas do século vinte e contemporâneas: as interpretaçóes marxistas, o protagonismo feminista, o direito das mulheres, o direito burguês de herança, a guarda judicial dos filhos, a burguesia industrial, o subproletariado de origem rural tornado pequeno-burguês urbano, etc. - todas essas discussóes contemporâneas pulsam ao fundo de nossas consciências, em pensamentos, quando vemos uma história como esta, contada em escritura cinematográfica.

O cinema pasoliniano tem forte ligação com o que ele chamava de subproletariado, o qual ele via nessa época sob a visão marxista de 1968/69, de maneira idealizada - mais tarde iria dolorosamente criticá-lo e criticar-se, quando se deu conta de que o subproletariado urbano havia perdido os valores puros do mundo agrícola de onde veio, e se tornado pequeno-burguês. Há contradição aí? Não importa muito saber ou detectá-la.

Em Abjuración de la trilogia de la vida (1977, p. 62, tradução livre), o diretor escreveu:

Se aqueles que eram outrora aquilo puderam transformarse agora nisto, significa que já eram assim potencialmente, portanto também o seu modo de ser de outrora fica, pelo presente, desvalorizado. Os jovens e rapazes do subproletariado romano - que são os mesmos que projetei na velha $\mathrm{e}$ resistente Nápoles e, depois, nos países pobres do Terceiro Mundo - se agora são imundícia humana, é porque outrora já o eram potencialmente: eram, portanto, imbecis obrigados a serem adoráveis, esquálidos criminosos obrigados a ser simpáticos malandros, covardes ineptos obrigados a ser santamente inocentes, etc. A derrocada do presente implica também a derrocada do passado. A vida é um monte de insignificantes e irônicas ruínas.

Isso ele escreveu em 1975, e Medeia foi filmado em 1969, porém essa crítica ao novo homem do subproletariado pode ser lida em retrospecto visual em relação a Jasão, o aristocrata in-vestido de novo homem burguês do capitalismo.

No entanto, enquanto Jasão se transforma, Medeia permanece a mesma, a 
aristocrata poderosa, rica e mimada neta do Sol, acostumada a fazer valer sua vontade e seus sentimentos, que sofre e pratica males humanos - ciúme, traição, assassinato, perversidade - em doses potencializadas.

Mas o que teriam pensado essas duas pessoas que se unem, separam-se, enfrentam-se no filme? Certamente não em suas origens, mas em seus desejos. Mas como poderíamos saber o que um personagem cinematográfico pensa? Somente se ele nos contar seu pensamento e, mesmo assim, isso não quer dizer que saibamos o que alguém, real ou personagem, pensa, ao no-lo contar.

Cinema é arte do comportamento: temos que deduzir tudo pelas aparências, pelos gestos, pelo que é visível. Tanto na vida real quanto no cinema, nunca vemos o que alguém pensa, o pensamento é invisível. Lembremos ainda que o cinema mostra o real, simulando-o com o próprio real: linguagem do real.

Onde está, em suma, a diferença, certamente não desprezível, entre texto literário tradicional e escritura que se refere à escritura cinematográfica? A grande linha de demarcação entre os dois gêneros está, sobretudo, na possibilidade de contar diretamente o pensamento dos personagens: em um romance é possível transcrever fielmente aquilo que alguém pensa e estender-se como quiser sobre o seu silêncio, misturando recordaçốes e reflexôes. [...].

Para o cinema, pelo contrário, são fisiologicamente vetadas as incursóes nas profundezas do consciente e inconsciente das pessoas. $\mathrm{O}$ cinema, arte para o órgão da visão, pretende que o autor consiga colocar em cena os sentimentos de um personagem somente através de seu comportamento, de seu agir, e de seu dizer (discurso indireto livre). A câmera cinematográfica náo tem condiçóes de penetrar no interior dos homens, de fotografá-los em seu próprio magma espiritual. [...] Em consequência, a narração cinematográfica adota um procedimento com uma forte valência visual. (Cerami, 2001, p. XXXIV-XXXV).

III

O fim.

Creonte, o rei de Corinto, quer extraditar Medeia da cidade juntamente com seus filhos com Jasão. Ela sabe que, se eles forem extraditados, perderão a cidadania e ficarão na miséria; diríamos hoje: rebaixados de classe social. Ela percebe também que não tem garantias de que Jasão, interessado na ascensão social através desse novo casamento, vá defender seus filhos, que poderão tornar-se um empecilho mais tarde: quando o próprio Jasão tornar-se rei, os filhos poderão reivindicar herança e direitos à coroa. 
Referindo-se à atitude de Jasão, incerta e ambígua, e ao casamento dele com a princesa Glaucia, a ama e o preceptor dos filhos de Medeia comentam essa nova aliança, aludindo ao vínculo matrimonial:

Fala o preceptor:

Ouvi dissimuladamente uma conversa [...] Eles diziam que os filhos iam ser expulsos de Corinto, e a mäe com eles, por Creonte, nosso rei. Não sei se esse rumor é exato, antes não seja!

Ama: E deixará Jasão tratarem desse modo os filhos apesar do desentendimento que se manifestou entre a mãe deles e ele? Preceptor: Cede a aliança antiga em face de uma nova e ele já não se mostra amigo desta casa. (Eurípedes, 1991, 90-94, p. 22).

Medeia tenta convencer Creonte a deixá-la ficar em Corinto com seus filhos e não consegue. Pede, então, a Jasão que proteja seus filhos e convença o rei, através de Glaucia, sua filha. Para agradá-la, Medeia manda os filhos levarem-lhe um manto, colares e tiara, jóias maravilhosas, porém enfeitiçadas.

Ao vesti-las, Glaucia sente-se enlouquecer, queimar-se por dentro. Seu pai tenta salvá-la, abraça-a e enlouquece também: ambos se matam do lado de fora das muralhas da cidade.

Medeia entra em casa.

A neta do Sol, filha de reis e feiticeira, como vingança pela traição de Jasão e para fazê-lo sofrer, banha os dois filhos, nina-os, coloca-os para dormir e os mata.

O filme termina assim, a tragédia também.

Em certa versão do mito, Medeia foge numa carruagem ensolarada, e Jasão volta à cidade de origem e assume o governo de Iolco.

\section{Referências bibliográficas}

CERAMI, V. La trascrizione dello sguardo. In: PASOLINI, P. P. Per il cinema. Miláo: Arnoldo Mondadori Editore, 2001. v. 1.

EURÍPEDES. Medeia. In: EURÍPEDES. Medeia, Hipólito, As Troianas. Traduzido do grego por Mário da Gama Cury. Rio de Janeiro: Jorge Zahar, 1991.

FERRETTI, D. Entrevista. [2005]. Disponível em: <http://www.berlinale-talentcampus. de/story/91/1691.html>. Acesso em: 23 maio 2011.

MEDEIA. Direção e roteiro: Pier Paolo Pasolini. Produçáo: Franco Rossellini e Marina Cicogna. Intérpretes: Maria Callas Massimo Girotti; Laurent Terzieff; Giuseppe Gentile; Margareth Clémenti e outros. Roma: San Marco SpA; Paris: Le Films Number One; Frankfurt: Janus Film und Fernsehen, 1969. 1 filme (110 min). 
ORTEGA Y GASSET, J. Prólogo. In: CÓRDOBA, I. H. El collar de la palomba. Madrid: Alianza Editorial, 2010.

PASOLINI, P. P. Abjuración de la trilogia de la vida. Cartas luteranas. Madrid: Editorial Trotta, 1997. p. 61-64.

URUTÁGUA - revista quadrimestral acadêmica multidisciplinar, Departamento de Ciências Sociais da Universidade Estadual de Maringá (DCS/UEM), Maringá, Paraná, Brasil, n. 14, dez. 2007/jan./fev./mar. 2008. Disponível em: http://www.urutagua.uem. br/014/14lopes.htm. Acesso em: 30 maio 2011.

Recebido em 15 de julho de 2011 e aprovado em 23 de setembro de 2011. 